\title{
Space radiation research in Europe: flight experiments and ground-based studies
}

\author{
M. Durante · G. Reitz • O. Angerer
}

Received: 31 October 2009 / Accepted: 22 May 2010 / Published online: 8 June 2010

(C) Springer-Verlag 2010

\begin{abstract}
Exposure to space radiation has long been acknowledged as a potential showstopper for long-duration manned interplanetary missions. In an effort to gain more information on space radiation risk and to develop countermeasures, NASA initiated several years ago a Space Radiation Health Program, which is currently supporting biological experiments performed at the Brookhaven National Laboratory. Accelerator-based radiobiology research in the field of space radiation research is also under way in Russia and Japan. The European Space Agency (ESA) supports research in the field in three main directions: spaceflight experiments on the International Space Station; modeling and simulations of the space radiation environment and transport; and, recently, ground-based radiobiology experiments exploiting the high-energy SIS18 synchrotron at GSI in Germany (IBER program). Several experiments are currently under way within IBER, and so far, beams of $\mathrm{C}$ and Fe-ions at energies between 11 and 1,000 MeV/n have been used in cell and tissue targets.
\end{abstract}

M. Durante ( $\square)$

Biophysics Department,

GSI Helmholtzentrum für Schwerionenforschung,

Planckstraße 1, 64291 Darmstadt, Germany

e-mail: M.Durante@gsi.de

\section{Durante}

Technische Universität Darmstadt, Institut für Festkörperphysik, Hoschshulstraße 3, 64289 Darmstadt, Germany

G. Reitz

Radiation Biology Department, DLR, Köln, Germany

O. Angerer

ESA, ESTEC, HSF-USL, Nordwijk, The Netherlands

\section{Introduction}

Space exploration is a grand adventure for humankind with the potential for exciting discoveries that capture our imagination and benefits society. However, exploration and colonization of the solar system must be achievable with minimal health detriment. Exposure to galactic cosmic rays (GCR) and solar proton events presents significant but poorly understood risks for carcinogenesis and degenerative diseases (Durante and Cucinotta 2008).

NASA has acknowledged that radiation risk represents a potential showstopper for manned exploration and colonization of the Solar system in its strategic program (NASA 1998). Most of our knowledge on the biological effects of cosmic radiation is based on experiments performed at accelerators (Durante and Kronenberg 2005), and indeed, the NASA Space Radiation Laboratory (NSRL) accelerator facility in Brookhaven was totally funded by NASA to address some of the open research issues, especially to reduce uncertainties on the cancer risk estimates (Cucinotta and Durante 2006). The deterministic computer code HZETRN based on the Boltzmann transport equation was developed and constantly upgraded and coupled to a biological model for calculation of equivalent doses and risk (Wilson et al. 2002).

Europe has an active program in space experiments on the effects on microgravity and space radiation (Bücker et al. 1984), especially using excellent active dosimeters such as ALTEINO (Casolino et al. 2007) and ALTEA (Zaconte et al. 2008), and space radiation transport calculations, primarily electing to use Monte Carlo codes such as Geant4 (Ersmark et al. 2007). Moreover, a groundbased radiobiology program exploiting the high-energy SIS18 synchrotron at GSI in Germany has been successfully launched (Durante et al. 2007). This program for 
Investigations into Biological Effects of space Radiation (IBER) is complementary to the NASA program running in Brookhaven and to other space radiobiology activities ongoing at accelerators in Russia (Antipov et al. 1994) and Japan (Ando 2001).

Europe has a specific excellence in radiobiology at accelerators, driven by the ion therapy programs running in Germany and planned in other countries (Durante and Loeffler 2010). On July 6-10, 2009, the 1st ESA-IBER Investigators' Workshop was held in Cologne (Germany), in a large joint symposium together with the 20th NASA Annual Space Radiation Health Investigators' Workshop (organized by Francis Cucinotta, NASA), and the 12th Workshop on Ion Beam in Biology and Medicine (IBIBAM, organized by Gerhard Kraft, GSI). The symposium also included the 5th International Workshop on Space Radiation Research. Papers from the 4th Workshop in 2007 were previously published in this journal (Cucinotta et al. 2007). This large Heavy Ion in Therapy and Space Symposium was organized by the Radiation Biology department of the German Space Agency (DLR) with Günther Reitz as main organizer and provided a unique opportunity to have joint discussions of physicists, biologists, physicians, engineers, chemists, etc. interested in heavy-ion effects either for cancer therapy or for radioprotection in space travel. A number of papers from this symposium are published in this issue of Radiation and
Environmental Biophysics. Here, we will concentrate on the current European programs in space radiation dosimetry and biology.

\section{Spaceflight dosimetry}

Several European instruments have been used in space for dosimetry (Reitz et al. 2005; Pugliese et al. 2010), for accurate measurements of the radiation spectrum behind shielding, and for science experiments that include, for instance, investigation of the correlation between particle fluxes and light flashes (Casolino et al. 2003).

In recent years, the MATROSHKA experiment, supported by ESA and coordinated by DLR in cooperation with 20 research institutes, has provided a valuable dataset of organ doses in space which can be used to benchmark current models (Reitz et al. 2009). MATROSHKA (Fig. 1) is designed as an anthropomorphic upper torso phantom, with 33 slices, each $25 \mathrm{~mm}$ in thickness. A base structure houses the electronic boxes for data acquisition and data transmission of the internal temperature and pressure as well as the active radiation detector sensors. A carbon fiber container with a mass density of $\sim 0.5 \mathrm{~g} / \mathrm{cm}^{2}$ simulates the shielding distribution of an astronauts' extravehicular activity suit (EVA suit). The phantom torso is equipped with passive thermoluminescence

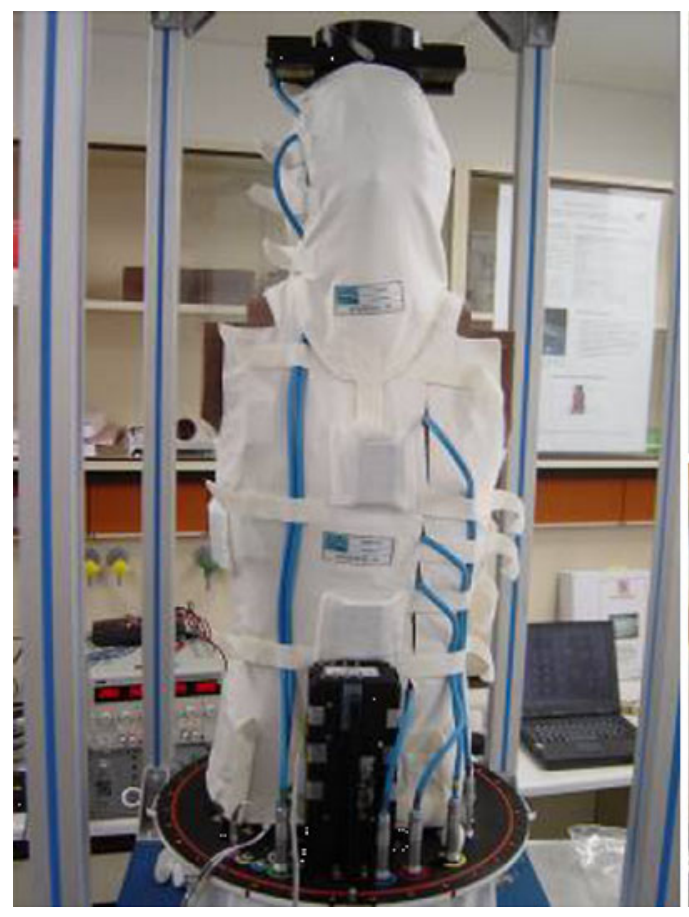

Fig. 1 Left: The MATROSHKA facility without container; the phantom mounted on the Base Structure that houses the electronics and dressed with the Poncho equipped with a series of passive detectors

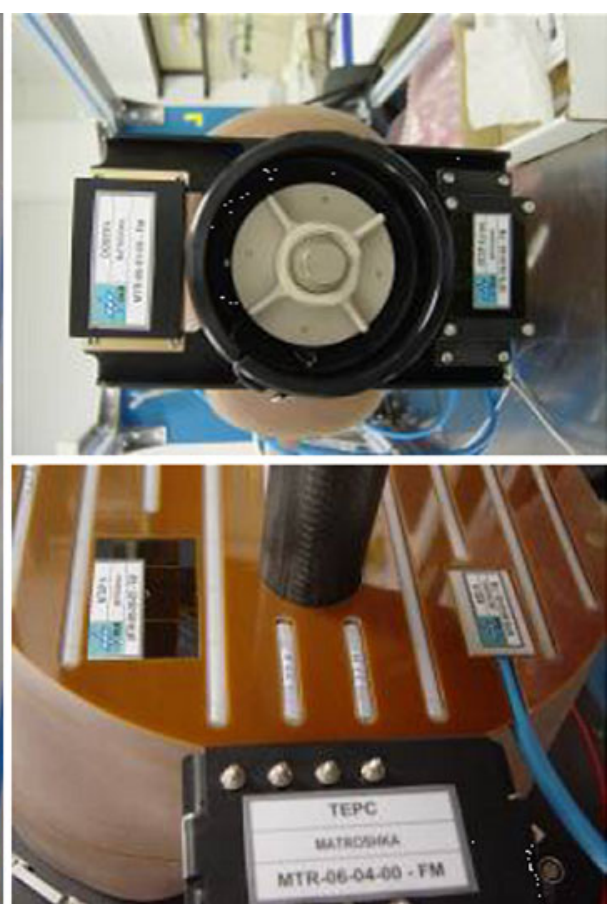

(TLDs, CR39). Right: the upper slides shows the DOSTEL sensor head on the top of the phantom; the lower slide shows the polyethylene tubes, the passive organ dose package and an SSD in a phantom slice 
Table 1 A list of high-energy ion accelerators in Europe that could be exploited for ground-based space radiation research

\begin{tabular}{|c|c|c|c|c|c|c|c|c|c|}
\hline \multirow[t]{2}{*}{ Accelerator } & \multirow[t]{2}{*}{ Particle } & \multirow[t]{2}{*}{$\begin{array}{l}\text { Energy } \\
(\mathrm{MeV} / \mathrm{u})\end{array}$} & \multicolumn{2}{|c|}{$\begin{array}{l}\text { Biological } \\
\text { Exposure Setup }^{\mathrm{a}}\end{array}$} & \multirow[t]{2}{*}{ Dosimetry $^{\mathrm{b}}$} & \multirow[t]{2}{*}{$\begin{array}{l}\text { Active } \\
\text { scanning }\end{array}$} & \multirow[t]{2}{*}{ Microbeam } & \multirow[t]{2}{*}{ Support $^{\mathrm{c}}$} & \multirow[t]{2}{*}{ EU Support } \\
\hline & & & Cells & Animals (\#) & & & & & \\
\hline JYFL, Jyväskylä (Finland) & $\mathrm{N}-\mathrm{Xe}$ & 9.3 & & & + & & & & \\
\hline CYCLONE, Louvain (Belgium) & $\mathrm{C}-\mathrm{Ar}$ & $3.75-10$ & & & + & & & & \\
\hline \multirow[t]{2}{*}{ HIT, Heidelberg (Germany) } & $\mathrm{H}$ & $200-400$ & + & + & + & + & & & \\
\hline & $\mathrm{C}$ & & & & & & & & \\
\hline PSI, Villigen & $\mathrm{H}$ & $72-254$ & & & + & + & & & \\
\hline \multirow[t]{3}{*}{ INFN Italy: LNL, Legnaro } & $\mathrm{H}$ & $2.5-30$ & $(+)$ & & + & & $(+)$ & & \\
\hline & $\mathrm{He}$ & 3.5 & & & + & & & & \\
\hline & $\mathrm{Au}$ & 1.5 & & & & & & & \\
\hline \multirow[t]{4}{*}{ LNS, Catania } & $\mathrm{H}$ & $62-80$ & $(+)$ & & + & & & & \\
\hline & $\mathrm{C}$ & $23-80$ & & & & & & & \\
\hline & $\mathrm{Ar}$ & 40 & & & & & & & \\
\hline & $\mathrm{Au}$ & 23 & & & & & & & \\
\hline \multirow[t]{4}{*}{ TSL, Uppsala (Sweden) } & $\mathrm{H}$ & 180 & + & & + & & & & \\
\hline & $\mathrm{He}$ & 73.3 & & & & & & & \\
\hline & $\mathrm{O}$ & 45 & & & & & & & \\
\hline & $\mathrm{Xe}$ & 9.61 & & & & & & & \\
\hline \multirow[t]{3}{*}{ GANIL, Caen (France) } & $\mathrm{C}, \mathrm{O}, \mathrm{Ne}, \mathrm{Ar}$ & 95 & + & $(+)$ & + & + & & + & + \\
\hline & $\mathrm{Ni}$ & 70 & & & & & & & \\
\hline & $\mathrm{U}$ & 24 & & & & & & & \\
\hline $\begin{array}{l}\text { GSI, Darmstadt: } \\
\text { (Germany) UNILAC }\end{array}$ & $\mathrm{H}-\mathrm{U}$ & 11.4 & + & & + & & + & + & + \\
\hline SIS 18 & $\mathrm{H}-\mathrm{U}$ & $100-2,000$ & + & $(+)$ & + & + & & + & + \\
\hline FAIR (in progress) & $\mathrm{H}-\mathrm{U}$ & $<45,000$ & + & + & + & + & & + & + \\
\hline
\end{tabular}

The presence of infrastructures for radiobiology is also indicated. A plus in bracket (+) indicates the presence but with limitations

a Specialized exposure facility for biological samples like DNA probes and cultured cells, plus tissue culture laboratories available for sample preparation and processing

${ }^{\mathrm{b}}$ Exact dosimetry in the full range of particle fluencies of $10^{5}-10^{8} / \mathrm{s}$ and homogeneity better than $5 \%$

${ }^{c}$ Technical support (manpower) in sample exposure and laboratory work

${ }^{\mathrm{d}}$ Laboratory is acknowledged by the EU as an international facility, and travel and housing of guests are supported

detectors (TLD) placed in 354 polyethylene tubes, which are accommodated in the 33 slices, enabling determination of the absorbed dose and depth dose distribution at 800 measurement points in a $2.5 \mathrm{~cm} x / y / z$ grid. Combination of TLD detectors and nuclear track etch detectors (CR39) is put together in polyethylene boxes $(60 \times$ $40 \times 25 \mathrm{~mm}$ ) at selected organ locations. For the determination of the skin dose, detectors are sewed into polyethylene stripes directly on the phantom surface. Seven active radiation detector monitors are distributed in the simulated organ regions $-5 \times$ silicon scintillators (SSDs) for the determination of the neutron component, and one silicon telescope (DOSTEL) is located on top of the head of the phantom providing particle fluences and linear energy transfer (LET) spectra. Altogether,
MATROSHKA uses more than 6,000 detectors. MATROSHKA was launched in 2004 and exposed outside the ISS-as a "simulated astronaut" performing an EVA for 539 days-followed by three exposure periods inside ISS. Simulations of the MATROSHKA experiment using the PHITS code are published in this issue (Sihver 2010).

The relationships between the skin- and organ-absorbed doses obtained in EVA show a steep gradient between the doses in the uppermost layer of the skin and the deep organs with a ratio close to 20 . This decrease which is due to the body self-shielding and a concomitant increase in the radiation quality factor by 1.7 with depth in the body highlight the complexities of an adequate dosimetry of space radiation. 


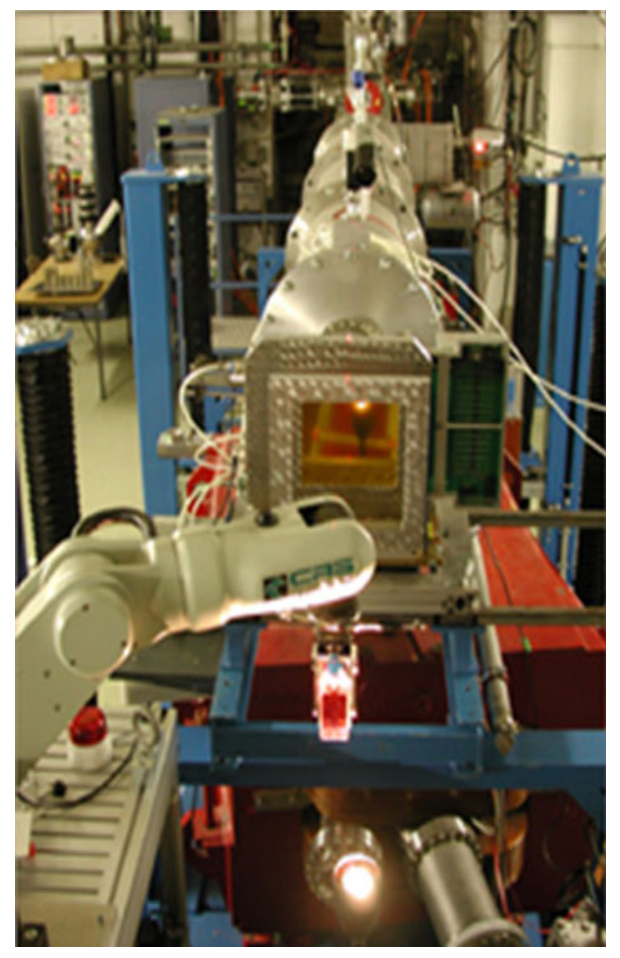

Fig. 2 The high-energy irradiation facility in Cave A at GSI. The robotic arm moves the samples (in flasks) to the beam position for the required exposure time. Beam delivery is by spot-scanning of the flask. This is a general-purpose facility for irradiation of in vitro samples with high-energy heavy ions

\section{European accelerator-based space radiation research project}

Following the recommendation of the IBER study team (IBER 2006), ESA issued in 2008 an announcement of opportunity (AO-IBER) for ground-based radiobiology research using the GSI accelerator facility.

The choice of the GSI facility was based on a careful evaluation of the different accelerators available in Europe for these studies (Table 1). GSI has an outstanding reputation in the field of heavy-ion radiobiology and can provide the following irradiation facilities to external investigators:

- High-energy ( $<2 \mathrm{GeV} / \mathrm{n}$ ) Cave A (Fig. 2)

- High-energy $(<2 \mathrm{GeV} / \mathrm{n})$ Cave M

- Low-energy $(<15 \mathrm{MeV} / \mathrm{n})$ UNILAC facility

- Low-energy microbeam (spatial resolution about $1 \mu \mathrm{m}$ )

- X-ray machine $(250 \mathrm{kVp}$, dose-rate $<6 \mathrm{~Gy} / \mathrm{min})$

The main topics recommended by the IBER study team for ground-based investigations in Europe are provided in Table 2 (IBER 2006). Fourteen proposals have been selected within the AO-IBER, and the topics are summarized in Table 3. It is noteworthy that most topics are related to noncancer effects, whereas the NASA program in Brookhaven has a strong emphasis on cancer risk. Noncancer effects should be carefully addressed before the mission to Mars, and they are even less understood than carcinogenesis (NASA 2009). The use of innovative biological test models is highly desirable, and in this issue, innovative models of the mouse aorta (Soucy et al. 2010) in the NASA program and organotypic brain slices from the ESA program (Merz et al. 2010) are described.

In the first IBER experiments performed at GSI in the Summer 2009, investigators used ${ }^{12} \mathrm{C}$ and ${ }^{56} \mathrm{Fe}$ ions at energies between 11 and 1,000 MeV/n. These ions were not selected by chance-experiments with carbon are also important for heavy-ion therapy, whereas iron is the major contributor to dose equivalent in space. Nickel and nitrogen ions have also been used in the spring 2010 run. In future experiments, it will be important to exploit the GSI microbeam (Fig. 3). In space, astronauts are exposed to charged particles from $Z=1(\mathrm{H})$ up to $Z=28(\mathrm{Ni})$, but the probability of a hit to a specific single cell in the human body is low. In fact, about $50 \%$ of the human cells (nuclear cross-section approximately $100 \mu \mathrm{m}^{2}$ ) are hit by a particle of the CNO group during 1-year travel to Mars in solar minimum. Particle microbeams can deliver single charged particles of different charge and energy to single cells from different tissues, and microbeam studies are therefore very useful for improving current risk estimates for long-term space travel. In principle, 2D in vitro cell cultures can help establishing basic molecular mechanisms, but they are not sufficient to extrapolate risk, given the substantial evidence proving tissue effects to be essential in determining the response to radiation insult. Instead, 3D tissue or animal systems represent a more promising target for space radiobiology using microbeams (Durante 2009).

\section{Conclusions}

Space radiation research is becoming a high priority in Europe, as already it is in the USA. The uncertainty on space radiation risk must be reduced to reach an "acceptable" level (Schimmerling 2010) for human colonization of the Solar system, and ground-based research is a key step in this process. The current roadmap for radiation protection studies in Europe (Belli et al. 2010) gives great emphasis on studies on quality factors, dose-rate effects, noncancer effects, and the shape of the dose-response curve at low doses, all topics extremely relevant for space radiation protection as well. In addition to consolidated activities in modeling of the space radiation environment and dosimetry and spaceflight experiments on ISS, the recent groundbased IBER radiobiology program has the potential to attract many European groups with expertise in radiobiology 


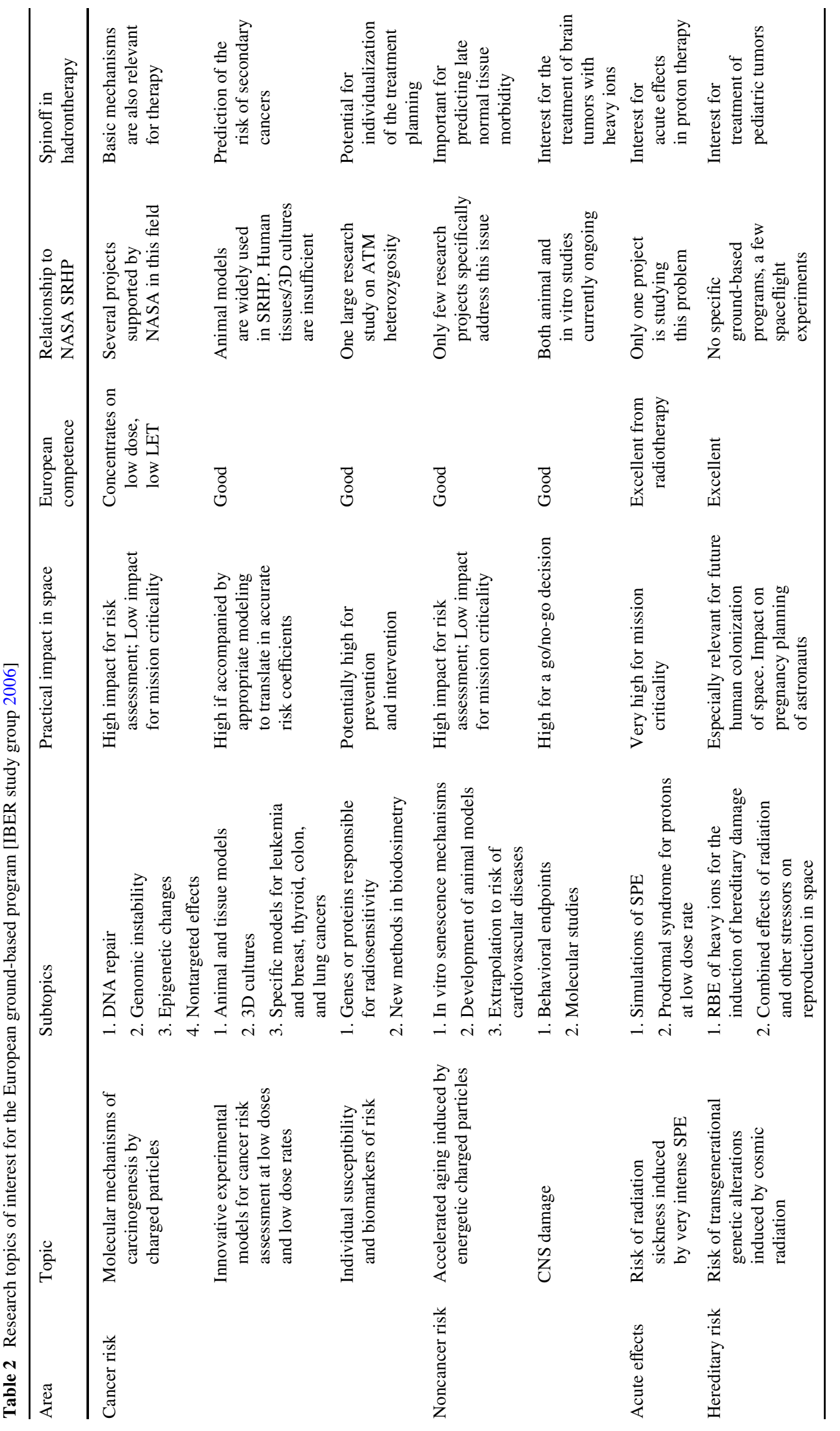




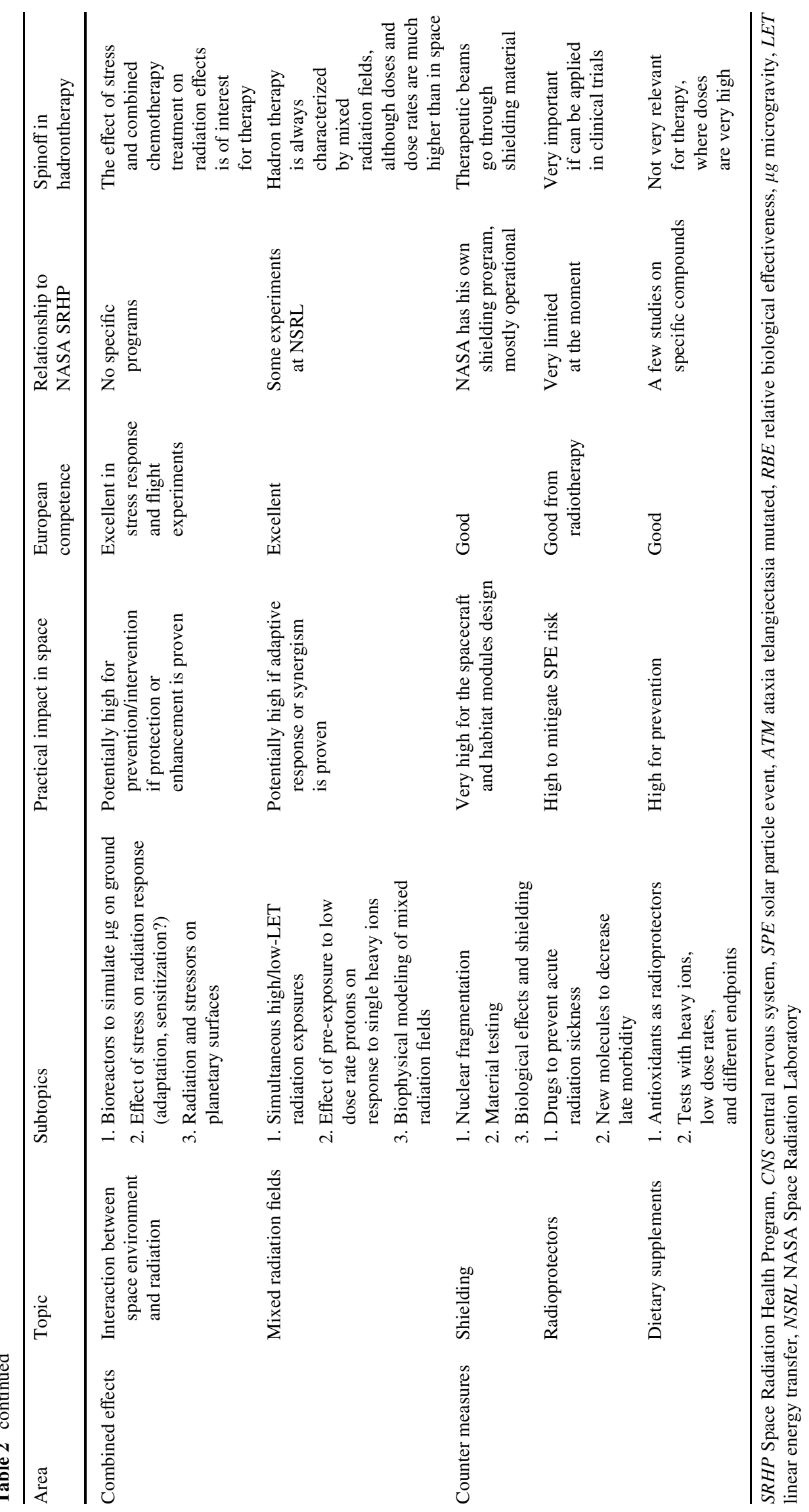


Table 3 Topics of the experiments selected within the ESA-IBER project

\begin{tabular}{|c|c|c|}
\hline Experiment topic & Area (Table 2) & Topic/subtopic \# (Table 2) \\
\hline Effects of heavy ions on neural stem cells of the hippocampus & Noncancer risk & CNS damage $/ 2$ \\
\hline $\begin{array}{l}\text { Molecular mechanisms of heavy-ion-induced } \\
\text { mucositis as studied in organotypic cultures }\end{array}$ & Noncancer risk & $\begin{array}{l}\text { Accelerated aging induced } \\
\text { by energetic charged particles } / 2\end{array}$ \\
\hline Effects of heavy ions on photoreceptors & Noncancer risk & $\begin{array}{l}\text { Accelerated aging induced } \\
\text { by energetic charged particles } / 2\end{array}$ \\
\hline Low-energy electrons in solids & Countermeasures & Shielding/2 \\
\hline Germ-cell mutagenesis in mice & Hereditary risk & $\begin{array}{l}\text { Risk of transgenerational genetic } \\
\text { alterations induced by cosmic radiation/1 }\end{array}$ \\
\hline Radioprotection by pTyr & Countermeasures & Radioprotectors/2 \\
\hline Backup repair pathways & Cancer risk & $\begin{array}{l}\text { Molecular mechanisms of } \\
\text { carcinogenesis induced by charged particles/1 }\end{array}$ \\
\hline Signaling pathways and DNA repair & Cancer risk & $\begin{array}{l}\text { Molecular mechanisms of } \\
\text { carcinogenesis induced by charged particles } / 3\end{array}$ \\
\hline Heavy-ions effects in osteoblasts & Noncancer risk & $\begin{array}{l}\text { Accelerated aging induced by } \\
\text { energetic charged particles } / 1\end{array}$ \\
\hline Late cardiovascular effects of space radiation & Noncancer risk & $\begin{array}{l}\text { Accelerated aging induced by } \\
\text { energetic charged particles } / 3\end{array}$ \\
\hline MATROSHKA & Combined effects & Mixed radiation fields/ 1 \\
\hline Heavy ions and ion channels & Noncancer risk & $\begin{array}{l}\text { Accelerated aging induced by } \\
\text { energetic charged particles/1 }\end{array}$ \\
\hline Heavy ions and gene splicing & Cancer risk & $\begin{array}{l}\text { Individual susceptibility and } \\
\text { biomarkers of risk/1 }\end{array}$ \\
\hline
\end{tabular}
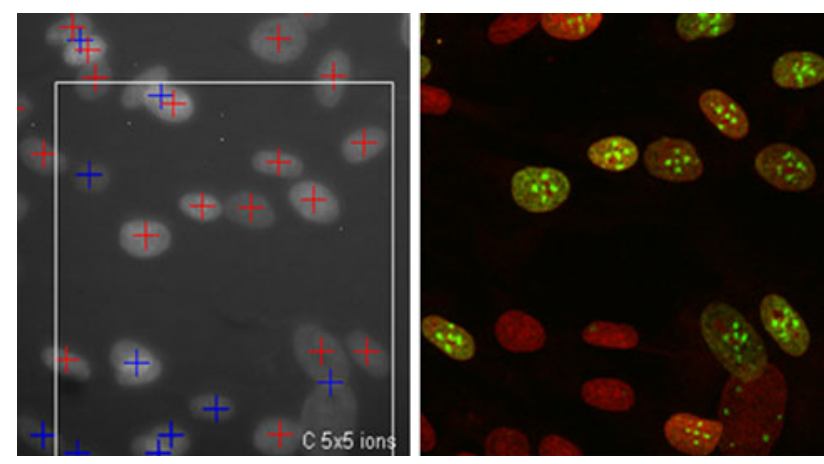

Fig. 3 The microbeam at GSI can deliver single heavy ions at low energy with a resolution of about $1 \mathrm{~mm}$. The figure shows the delivery of 5 carbon particles in the nuclei of human cells (left) and subsequent detection of the hits by immunofluorescence of repair proteins (right)

or biomedicine in the field of heavy-ion research and space radiation protection. Greater involvement of the international community is needed, especially with the goal of developing effective countermeasures before sending a manned mission to Mars, which hopefully will occur in this century.

Acknowledgments The IBER experimental activity is supported by ESA Contract \# RFQ-3-12324/08/NL/VJ. The authors are grateful to Dr. Francis A. Cucinotta (NASA) for the organization of the International Workshop on Space Radiation Research and his useful comments on this manuscript and on the European program in general. We also thank Dr. Gerhard Kraft for the organization of the IBIBAM meeting, and Dr. Christa Baumstark-Khan for the excellent contribution in the organization of the symposium. Finally, we are grateful to the editors of this journal, Drs. Werner Rühm and Anna Friedl, for their hard work in getting the manuscripts peer reviewed and for their interest in heavy-ion research.

\section{References}

Ando K (2001) High LET radiobiology at NIRS-current status and future plan. Phys Med 17:S292-S295

Antipov VV, Petrov VM, Shafirkin AV, Gorlov VV, Fedorenko BS, Chertkov KS (1994) Space radiobiology program in Russia. Adv Space Res 14:139-144

Belli M, Ottolenghi A, Weiss W (2010) The European strategy on low dose risk research and the role of radiation quality according to the recommendations of the "ad hoc" high level and expert group (HLEG). Radiat Environ Biophys, this issue. doi:10.1007/ s00411-010-0284-2

Bücker H, Horneck G, Facius R, Reitz G, Schäfer M, Schott JU, Beaujean R, Enge W, Schopper E, Heinrich H, Beer J, Wiegel B, Pfohl R, François H, Portal G, Bonting SL, Graul EH, Rüther W, Kranz AR, Bork U, Koller-Lampert K, Kirchheim B, Starke ME, Planel H, Delpoux M (1984) Radiobiological advanced biostack experiment. Science 225:224-226

Casolino M, Bidoli V, Morselli A, Narici L, De Pascale MP, Picozza P, Reali E, Sparvoli R, Mazzenga G, Ricci M, Spillantini P, Boezio M, Bonvicini V, Vacchi A, Zampa N, Castellini G, Sannita WG, Carlson P, Galper A, Korotkov M, Popov A, Vavilov N, Avdeev S, Fuglesang C (2003) Dual origins of light flashes seen in space. Nature 422:680

Casolino M, Altamura F, Minella A, Minori M, Picozza P, Reali E, Esposito A, Bedogni R, Mazzenga G, Ricci M, Durante M, Pugliese 
M, Roca V, Galper A, Korotkov M, Popov A, Bengin V, Lobascio C, Guarnieri V, Fortezza R, Castagnolo D (2007) The SileyeALTCRISS experiment on board the international space station. Nucl Instr Meth A572:235-236

Cucinotta FA, Durante M (2006) Cancer risk from exposure to galactic cosmic rays: implications for space exploration by human beings. Lancet Oncol 7:431-435

Cucinotta FA, Durante M, Petrov V (2007) Fourth international workshop on space radiation research. Radiat Environ Biophys 46:8990

Durante M (2009) Applications of particle microbeams in space radiation research. J Radiat Res 50:A55-A58

Durante M, Cucinotta FA (2008) Heavy ion carcinogenesis and human space exploration. Nat Rev Cancer 8:465-472

Durante M, Kronenberg A (2005) Ground-based research with heavy ions for space radiation protection. Adv Space Res 35:180-184

Durante M, Loeffler JS (2010) Charged particles in radiation oncology. Nat Rev Clin Oncol 7:37-43

Durante M, Kraft G, O’Neill P, Reitz G, Sabatier L, Schneider U (2007) Preparatory study of a ground-based space radiobiology program in Europe. Adv Space Res 39:1082-1086

Ersmark T, Carlson P, Daly E, Fuglesang C, Gudowska I, Lund-Jensen B, Nieminen P, Pearce M, Santin G (2007) Influence of geometry model approximations on Geant 4 simulation results of the Columbus/ISS radiation environment. Radiat Meas 42:13421350

IBER study group (2006) IBER study final report. ESA publication $\mathrm{CR}(\mathrm{P})-4585$

Merz F, Müller M, Taucher-Scholz G, Rödel F, Stöcker H, Schopow K, Laprell L, Dehghani F, Durante M, Bechmann I (2010) Tissue slice cultures from humans or rodents: a new tool to evaluate biological effects of heavy ions. Radiat Environ Biophys, this issue. doi:10.1007/s00411-010-0293-1

NASA (1998) Strategic program plan for space radiation health research. NASA Headquarters, Washington, DC

NASA (2009) Human health and performance risks of space exploration missions. Chapters 6-7. NASA SP-2009-3405
Pugliese M, Bengin V, Casolino M, Roca V, Zanini A, Durante M (2010) Tests of shielding effectiveness of kevlar and nextel onboard the international space station (ISS) and the FOTON-M3 capsule. Radiat. Environ. Biophys., this issue. doi:10.1007/ s00411-010-0283-3

Reitz G, Beaujean R, Benton E, Burmeister S, Ts Dachev, Deme S, Luszik-Bhadra M, Olko P (2005) Space radiation measurements onboard ISS - the DOSMAP experiment. Radiat Prot Dosim 116:374-379

Reitz G, Berger T, Bilski P, Facius R, Hajek M, Petrov V, Puchalska M, Zhou D, Bossler J, Akatov Y, Shurshakov V, Olko P, Ptaszkiewicz M, Bergmann R, Fugger M, Vana N, Beaujean R, Burmeister S, Bartlett D, Hager L, Pálfalvi J, Szabó J, O’Sullivan D, Kitamura H, Uchihori Y, Yasuda N, Nagamatsu A, Tawara H, Benton E, Gaza R, McKeever S, Sawakuchi G, Yukihara E, Cucinotta F, Semones E, Zapp N, Miller J, Dettmann J (2009) Astronaut's organ doses inferred from measurements in a human phantom outside the international space station. Radiat Res 171:225-235

Schimmerling W (2010) Accepting space radiation risks. Radiat Environ Biophys, this issue. doi:10.1007/s00411-010-0286-0

Sihver L (2010) Simulations of the MATROSHKA experiment at the international space station using PHITS. Radiat Environ Biophys, this issue. doi:10.1007/s00411-010-0288-y

Soucy KG, Attarzadeh DO, Ramachandran R, Soucy PA, Romer LH, Shoukas AA, Berkowitz DE (2010) Single exposure to radiation produces early anti-angiogenic effects in mouse aorta. Radiat Environ Biophys, this issue. doi:10.1007/s00411-010-0287-z

Wilson JW, Tripathi RK, Qualls GD, Cucinotta FA, Prael RE, Norbury JW, Heinbockel JH, Tweed J, De Angelis G (2002) Advances in space radiation shielding codes. J Radiat Res 43:S87-S91

Zaconte V, Belli F, Bidoli V, Casolino M, Di Fino L, Narici L, Picozza P, Rinaldi A, Sannita WG, Finetti N, Nurzia G, Rantucci E, Scrimaglio R, Segreto E, Schardt D (2008) ALTEA: the instrument calibration. Nucl Instr Meth B 266:2070-2078 